Informal Logic

X.3, Fall 1988

\title{
Hedging as a Fallacy of Language*
}

\author{
GARY JASON Orange Coast College
}

While there has been considerable progress in the study of fallacies over the twenty years since the publication of Hamblin's excellent monograph on the subject, the treatment of the fallacies of language still remains much as it has always been. The usual suspects-equivocation, amphiboly, accent, composition, and division-are rounded up, and covered in an abbreviated fashion. In this paper I would like to discuss another fallacy of language, hedging, with an eye to broadening our view of fallacies of language. Specifically, I want to accomplish three things. First, I want to convince the reader that hedging is indeed common (and so should be added to the admittedly burgeoning list of standard fallacies). Second, I want to give an adequate theoretical (i.e., linguistic) treatment of the fallacy. Third, I want to show how the standard treatment of fallacies of language can be modified to include not only hedging, but other fallacies as well.

The fallacy of which I speak is exemplified by the following paradigm dialogue:

A: Henry is a totally selfish man.

B: I don't find him so-he once helped me find a job.

A: Well, about things that affect his wallet, he is totally selfish.

B: Yet he has on many occasions loaned money to his friends.

A: Well, about matters that affect his wallet he can be very selfish.

In this simple dialogue, A puts forward a claim, and then systematically evades B's counterevidence by weakening the initial claim. This is the first paradigm for the fallacy of hedging: a claim which is reasonably qualified at the beginning of the dialogue gets systematically weakened as the dialogue proceeds to avoid the thrust of counterevidence. In our paradigm, A simply will not come to grips with the substantial evidence $B$ has offered that Henry is not selfish. A's final weak claim is totally uninformative: anybody "can be" selfish, but is Henry selfish in fact? Contrast this with honest and non-fallacious backing down (i.e., retraction of an initial claim): A ought simply to have said, "I can't at the moment recall the incidents which lead me to think that Henry is selfish. Let me think about it. Maybe I'm wrong.',

Consider next this sample dialogue:

A: I believe that a true Christian is going to be less likely to commit crimes than a Moslem in the same circumstances.

B: That seems ridiculous to me. Look at the high crime rate in the U.S.A., which is a predominantly Christian country, and compare it to any Moslem country.

A: Ah, but the U.S.A. is different from Moslem countries in that those countries have harsh laws.

B: Well, okay then, just look at the U.S.A. Moslems in the U.S.A. have a lower crime rate than the general Christian population

A: Yes, but the so-called Christian population includes many people who are not true Christians.

In this paradigm, A puts forward a provocative claim, but hedges it round with the weasel words "true", and "so-called," which allow A to make it completely unclear to whom the term "Christian" applies. (The phrase "weasel word" is a col- 
loquial expression denoting qualifying phrases and detensifiers. Those are defined below.) Thus B's legitimate attempts to test A's claim with relevant evidence are frustrated. One wants to shout at A, "Look, do you genuinely believe that Christians are less criminally inclined than Moslems? Then allow us to bring some facts to bear on the issue. Otherwise, shut up and don't insult the Moslems." Again, contrast A's hedging with honest and non-fallacious backing down (i.e., retraction). A could simply have said "Well, maybe I'm wrong. Let me check into some statistics and we'll talk later." Temporarily retracting one's claim until he or she has better evidence for it is a logically acceptable way to save face; hedging is not.

Looking at the paradigms given above, then, we can define roughly the fallacy of hedging as the systematic weakening of a claim, or the putting forward of an unreasonably restricted initial claim, so as to avoid refutation. We will tighten this definition later.

It might fairly be asked whether the fallacy of hedging, defined as above, is so frequently committed in ordinary argumentation as to merit placing it on the list of "standard fallacies." The lexicon of fallacies is already large, and so the burden of proof is on the proposer of an addition to that lexicon to give some reason for further expansion.

In defense of adding hedging to the rogue's gallery of fallacies, I would point out how common it is for politicians to hedge in debates and news conferences to avoid taking positions which will cost them votes. Consider these examples from the second Reagan/Mondale presidential debate:

\section{Example I:}

Q: Mr. President, in the last few months it has seemed more and more that your policies in Central America were beginning to work. Yet just at this moment we are confronted with the extraordinary story of the C.I.A. guerrilla manual for the anti-Sandinista Contras, whom we are backing, which advocates not only assassinations of Sandinistas but the hiring of criminals to assassinate the guerrillas we are supporting in order to create martyrs. Is this not in effect our own state-supported terrorism?

Reagan: No, but I'm glad you asked that question because I know it's on many people's minds. I have ordered an investigation; I know that the C.I.A. is already going forward with one. We have a gentleman down in Nicaragua who is on military tactics, the Contras. And he drew up this manual. It was turned over to the agency head of the C.I.A. in Nicaragua to be printed, and a number of pages were excised by that agency head there, the man in charge, and he sent it on up here to the C.I.A., where more pages were excised before it was printed. But some way or other, there were 12 of the original copies that got out down there and were not submitted for this printing process by the C.I.A. Now those are the details as we have them, and as soon as we have an investigation and find out where any blame lies for the few that did not get excised or changed, we certainly are going to do something about that. We'll take the proper action at the proper time...

Q: Well, Mr. President, you are implying then that the C.I.A. in Nicaragua is directing the Contras there. I'd also like to ask whether having the C.I.A. investigate its own manual in such a sensitive area is not sort of like sending the fox into the chicken coop a second time.

Reagan: I'm afraid I misspoke when I said there is a C.I.A. head in Nicaragua. There's not someone there directing all of this activity. There are, as you know, C.I.A. men stationed in other countries in the world, and certainly in Central America, and so it was a man down there in that area that this was delivered to. And he recognized that what was in that manual was a direct contravention of my 
own executive order in December of 1981 , that we would have nothing to do with regard to political assassinations. ${ }^{\prime}$

In the first question, Reagan was asked about a provocative pamphlet allegedly produced by the C.I.A. His answer inadvertantly revealed that the C.I.A. had a man in charge of the military tactics of the Contras. When pressed, he hedged by saying there are C.I.A. men all over, and "it was a man down there in that area it was delivered to.",

\section{Example 2:}

$\mathrm{Q}$ : You've been quoted as saying that you might quarantine Nicaragua. I'd like to know what that means. Would you stop Soviet ships as President Kennedy did in 1962 and wouldn't that be more dangerous than President Reagan's covert war?

Mondale: What I'm referring to there is the mutual self-defense provisions that exist in the inter-American treaty, the so-called Rio Pact, that permits the nations, our friends in that region, to combine to take some steps, diplomatic and otherwise, to prevent Nicaragua when she acts irresponsibly in asserting power in other parts outside of her border, to take those steps, whatever they might be, to stop it.

In the question, Mondale is pressed on his position that he would possibly quarantine Nicaragua. In reply he hedges by talking about "our friends" combining with us to "take some steps," "diplomatic or otherwise," to prevent Nicaragua from acting "irresponsibly," "in asserting power." Some sort of action by the U.S. is being indicated, but the statement is so heavily qualified that the audience cannot tell what that action would be (thus how dangerous it would be), and what acts by Nicaragua would bring it on.

Another area in which hedging is common is in the statement of conditions in contracts, especially statements of guarantees which accompany various products. Such guarantees are often so heavily qualified as to be virtually useless. For example, one manufacturer of color photographic film guaranteed for quality puts the guarantee as follows:

This product, if defective in manufacture, labeling, packaging or shipping, or if damaged by us, will be replaced with like fresh film or purchase price refunded, at our option. This is your exclusive remedy and the limit of all contract or tort liability. Since color dyes may change in time, no warranty against any color change is expressed or implied. This film will not be replaced or purchase price refunded for any change in color.

A guarantee for color film which is hedged to be optional at the will of the manufacturer and to not apply to changes in color is a pretty worthless guarantee. Contrast this with a completely unhedged guarantee by Gillette Corporation for its razors: "Complete shaving satisfaction guaranteed or Gillette will replace free of charge or refund full purchase price." No qualifications are put forth, and the option for return lies solely with the customer.

If hedging is reasonably common, then why is it so commonly overlooked in accounts of fallacies of language? I suspect it is because fallacies of language are often equated with, or at least limited to, fallacies of ambiguity. ${ }^{2}$ To see why such an equation is wrong, reconsider fallacies of ambiguity for a moment. Is ambiguity per se bad? Surely not. Very likely most English words are ambiguous, and unavoidably so. As one semanticist has noted:

A moment's reflection will show that, far from being a defect of language, polysemy [ambiguity] is an essential condition of its efficiency. If it were not possible to attach several senses to one word, this would mean a crushing burden on our memory: we would have to possess separate terms for every conceivable subject we might wish to talk about. Polysemy is an invaluable factor of economy and flexibility in language; what is astonishing is not that the machine occasionally breaks down. but that it breaks down so rarely. ${ }^{3}$ 
Yet ambiguity is not normally a problem, because context usually makes the intended meaning clear. A word can be ambiguous without being used ambiguously in a given conversational context, as a number of logic texts have noted. ${ }^{4}$ What gives rise to a fallacy of ambiguity, i.e., a fallacious use of ambiguity, is the use of an ambiguous phrase one way in one premise of an argument and a different way in another premise (or the conclusion).

The vision that emerges here is that of a pervasive feature of language which is not normally bad, but which can be used to commit fallacies. Viewing fallacies in this way naturally leads us to ask what other pervasive features of language might be liable to misuse in argumentation.

One such feature that comes to mind is vagueness. Many words are vague, but context usually clarifies the meaning precisely enough for conversation to proceed. Vagueness is often useful, as when in law it allows room for the application of a term to new cases undreamt of when the original law was passed. But vagueness can be used to commit slippery slope fallacy, as when a person exploits the vagueness of a term to change the issue by degrees. Also, again as noted by several authors, vagueness can be used to equivocate, as when a person interprets a vague term loosely in one premise and strictly in another. ${ }^{5}$

Another feature of language liable to misuse is ladenness, by which I mean theoretical or emotional connotation. Terms can be theory-laden without being emotionladen ("electron," "ionic bond"), or emotion-laden without being theory-laden ("dirty rat," "punk"), or both theory- and emotion-laden ("IQ," “"nation"). Again, very likely most words are laden to some degree. Ladenness is not bad per se-it is how the ladenness is used that makes all the difference. It is not fallacious to use a theory-laden term in a context in which the theory at hand is not under question. It is not fallacious to use an emotion-laden term in a context in which the expression of emo- tion is the central purpose of the discourse. What is fallacious is to use laden language to presuppose that which is in dispute, or to persuade by emotion rather than reason.

Thus ladenness can be used to commit fallacies, but those fallacies usually are not presented as fallacies of language. Instead, ladenness which is used to presuppose that which is under dispute is usually termed "question-begging epithets" and lumped in as a form of petitio. Ladenness which is used to bias the description of evidence is characterized, if at all, as a kind of special pleading. ${ }^{6} \mathrm{I}$ am suggesting that fallacies of ladenness can be viewed as fallacies of language in their own right.

When we view fallacies of language more broadly as including fallacies of vagueness and ladenness as well as the traditional fallacies of ambiguity, the way is clear to include hedging. The feature of language that is misused in hedging is understatement. Let us turn our attention to that feature, so as to achieve a better theoretical understanding of hedging.

To understate a claim is to use words which diminish the force or content of the claim. Understatement can be achieved in a number of different ways. ${ }^{7}$ To begin with, the predicate of the claim can be diminished by any of a large group of adverbs of degree linguists call "detensifiers." A partial list of common English detensifiers is given below.

$\begin{array}{lll}\text { sort of } & \text { rather } & \text { relatively } \\ \text { kind of } & \text { more or less } & \text { quite } \\ \text { to some extent } & \text { moderately } & \text { a bit } \\ \text { barely } & \text { technically } & \text { basically } \\ \text { slightly } & \text { somewhat } & \text { in most respects } \\ \text { a fair amount } & \text { a little } & \text { in many respects } \\ \text { mainly } & \text { in part } & \text { in some respects } \\ \text { scarcely } & \text { almost } & \text { partially } \\ \text { practically } & \text { virtually } & \text { mildly }\end{array}$

For example, the claim "dogs are friendly" can be understated by detensification: "dogs are friendly," "dogs are somewhat friendly" and so on.

Detensification is only one method of understatement. Qualification is another. A 
qualifier is a phrase which limits the application of a predicate. Consider the following sequence of claims.

a) I will tell the truth.

b) I will tell you the truth.

c) I will tell you the truth about this matter.

d) I will tell you the truth about this matter today.

Notice that the claims get steadily weaker, because the area of application grows smaller (from telling everyone the truth about everything all the time, to telling one person the truth about one thing one time).

A third sort of understatement involves substituting contradictories for contraries. For instance, one can understate the claim "Kelly is bad" by saying "Kelly is not good." The contradictory of "good" ("not good") has been substituted for the contrary ("bad"). Calling a person "not good" weakens the claim, since it leaves open the possibility that the person is neither good nor bad.

So far we have been dealing with unmodalized assertions, that is, statements not containing modalities. But modalities are commonly used in statements. Words such as "'surely," "obviously," "evidently," "certainly," "clearly," "must," "has to" and so on indicate that the speaker has complete confidence in the claim. Words such as "think," "suppose," "believe," " "probably," "presumably," "supposedly," "should" and so on indicate confidence but some doubt. Words such as "guess," "seem," "can," "may/maybe/might," "possibly," "perhaps," "conceivably" and so on indicate less confidence and more doubt. Modalized assertions thus are open to a fourth sort of understatement, viz., the substitution of a weaker modality for a stronger one. The sequences below illustrate this sort of understatement.

1a) The rabbit must have gone down this hole.

1b) The rabbit should have gone down this hole.

1c) The rabbit may have gone down this hole. 2a) It is obviously a plane

2b) It is presumably a plane.

2c) It is conceivably a plane.

As a special case of the above, unmodalized statements can be understated by adding modalities-often parenthetically - as in the examples below.

la) The President is honest.

1b) The President is, I believe, honest.

2a) Pigs cannot dance.

2b) Pigs, to the best of my admittedly limited knowledge, cannot dance.

The point here is that when a speaker makes an assertion without a modality, the listeners assume that the speaker has no particular doubts about his statement. To parenthetically add a modality is a way to signal doubt, hence to understate.

These four devices for understatement (i.e., the use of detensifiers, the use of qualifiers, the substitution of contradictories for contraries, and the substitution of a weaker for a stronger modality) are of course not mutually exclusive. They can be used together, as in the cases below.

la) The President is honest.

1b) The President is probably honest about this matter.

2a) Hitler was evil.

2b) Hitler was, in my opinion, not good.

3a) Fred is dead.

3b) Fred, I rather suspect, is sort of dead.

(In $\mathrm{lb}$, a detensifier and a qualifier are used. In $2 b$, a parenthetical modality and contradictory are inserted. In $3 \mathrm{~b}$, a parenthetical and a detensifier are used.) ${ }^{8}$

I said earlier that understatement, like ambiguity, vagueness and ladenness, is a pervasive feature of language that has many logically unexceptionable uses. Quite often we understate to make a joke, as for instance when the humorists Bob and Ray claim they are heard "approximately Coast to Coast." The British are famous-not to say notorious-for using understatement as a humorous device. And quite often we use understatement to be courteous. Thus for 
example "I am not quite convinced that you are entirely right in this matter" is a very polite way of disagreeing with someone. Hedging, then, is not understatement, it is a fallacious use of understatement.

To be precise, hedging takes place in the following ways. Hedging of the first sort occurs when a proponent offers a thesis $\mathrm{T}$, and them presented with evidence $E$ which refutes $T$, substitutes $T^{\prime}$, where $T^{\prime}$ is a weakened version of $\mathrm{T}$ which is consistent with E. By "weakened version" we mean that $\mathrm{T}$ ' results from $\mathrm{T}$ by the addition of a detensifier, or a qualifier, or substituting the contradictory of a predicate for its contrary, or substituting a weaker modality for a stronger one. (In contrast, non-fallacious backing down involves simply retracting $\mathrm{T}$, where the retraction is explicit. If the arguer wishes to argue separately for 'T', that is another matter). Hedging of the first sort, like arguing to an irrelevant conclusion, tends to work when the illicitly substituted claim is deceptively similar to the original. Hedging of the second sort occurs when a claim is put forward which has so many qualifiers or detensifiers that it does not truly apply to the things that it appears to, or cannot be tested by counterevidence. Hedging of the second sort, like amphibolous predictions by fortune-tellers, tends to work when the emptiness of the claim is not immediately obvious to the audience.

Even adding understatement to ambiguity, vagueness and ladenness does not exhaust the list of the features of language that are misused to commit fallacies. For example, overstatement (hyperbole) is another common feature of language, often used to joke (as when Texans tell "tall tales"' about their State). But we can overstate to commit a fallacy, namely, a type of straw man. Generally speaking, the straw man fallacy is committed when a person inaccurately represents another person's position. ${ }^{9}$ Very often, perhaps usually, this misrepresentation takes the form of overstating the opponent's position in order to make it harder to defend. That is, one common technique of straw man involves either eliminating detensifiers, or ignoring key qualifications, or replacing contradictory predicates by contraries, or by substituting a stronger modality for a weaker one, in the opponent's position. (This form of straw man thus works in an opposite fashion from hedging, because in hedging an arguer attempts to understate his own position in order to make it easier to defend).

Still other examples of features of language which can be misused to commit fallacies can be given. We could include hypostatization (or reification), which is used to commit the fallacy of misplaced concreteness. ${ }^{10}$ And we might also consider the feature of synonymy, which can be put to good use (such as the elimination of repetition ${ }^{11}$ ), but which can also be used to commit the fallacy of begging the question.

The foregoing considerations suggest that the way to bring hedging into the informal logic curriculum, and possibly some other neglected fallacies as well, is to broaden of view of the fallacies of language, and what is involved in a fallacy of language. ${ }^{12}$

\section{Notes}

* My thanks to Perry Weddle, J. Anthony Blair, and Hans Hansen for their valuable criticisms of earlier drafts. Any errors that remain are my own.

1 The debate took place on October 21, 1984. All quotes from the debate are from The New York Times transcript of the debate, published October 22, 1989.

2 See for examples:

a) Copi, Irving, Introduction to Logic (7th ed.) N.Y.: Macmillan Pub. Co. (1986) pp. 113-122;

b) Thomas, Stephen Naylor, Practical Reasoning in Natural Language (3rd ed.) Englewood Cliffs, N.J.: PrenticeHall (1986) pp. 365-367;

c) Engel, S. Morris, With Good Reason, 
N.Y., St. Martin's Press (1986) pp. 89-116;

d) Toulmin, Stephen et al., An Introduction to Reasoning, N.Y.: Macmillan Pub. Co. (1979).

3 Ullmann, Stephen, Semantics, N.Y.: Barnes and Noble (1979) pp. 167-8.

4 See, for examples, Toulmin op. cit. p. 185 and Walton, Douglas, Informal Fallacies, Philadelphia: John Benjamins Pub. Co. (1987) p. 242.

5 See, for examples, Walton op. cit. p. 246, and Cederblom \& Paulsen, Critical Reasoning, Belmont, CA: Wadsworth Pub. Co. (1982) p. 59. The point that vagueness is not necessarily fallacious is made by Trudy Govier in her $A$ Practical Study of Argument Belmont, CA: Wadsworth Pub. Co. (1985) p. 356.

6 In particular, Govier (op. cit. p. 280) has noted that emotionally loaded language can vitiate the results of opinion polls.

7 For an extensive linguistic analysis of these and other techniques of understatement, see Huebler, Axel, Understatements and Hedges in English. Amsterdam: John Benjamines Pub. Co. (1983).

8 A pedagogic aside: I usually assign my students exercises designed to strengthen their ability to spot understatement. I give them ten or so modalized assertions and have them understate each all four ways. Example:

original claim: I am sure that Sam hates Jazz. detensifier added: I am sure that Sam hates Jazz somewhat. qualifier added: I am sure that Sam hates Jazz of this sort.

contradictory substituted: I am sure that Sam does not like Jazz.

weaker modality substituted: I believe that Sam hates Jazz.

9 This definition is close to that of Walton (op. cit. p. 10). Govier (op. cit. p. 109) has a more careful statement of straw man:

The straw man fallacy is committed when a person misrepresents an argument, theory, or claim, and then on the basis of that misrepresentation, claims to have refuted the position that he has misrepresented.

${ }^{10}$ Engels (op. cit. pp. 98-106) has a nice discussion of this fallacy.

11 See Ullmann, op. cit., p. 152 for a discussion of the use of synonymy to reduce repetition in prose.

12 One might even take the extreme position that there are no separate "fallacies of language." per se but rather that fallacious reasoning can occur because of misuse of language. For this extreme view to be made plausible, a case would have to be made for including the fallacies of ambiguity in some other category-say, as types of ignoring the issue. But whether or not such a case can be made is beyond our present topic.

Professor Gary Jason, Department of Philosophy, Orange Coast College, Costa Mesa, CA 92628 